AC 2007-2408: EFFECTIVENESS OF USING SYNCHRONOUS, TWO-WAY IP VIDEO TO TEACH BASIC ELECTRICAL KNOWLEDGE AND SKILLS TO FIRST-YEAR 4-H ELECTRIC MEMBERS

Roger Tormoehlen, Purdue University

Jeffrey Nagle, Purdue University 


\title{
Effectiveness of using Synchronous, Two-way IP Video to Teach Basic Electrical Knowledge and Skills to First Year 4-H Electric Members
}

\begin{abstract}
The purpose of this research study was to determine the effectiveness of using synchronous, two-way IP (Internet Protocol) video to teach knowledge and hands-on skills to elementary-aged youth in comparison to traditional, face-to-face educational methodologies. This study focused on the use of synchronous, two-way IP video to propagate knowledge and hands-on skill. Pretests and posttests were used to examine youth's knowledge and skill gains on material covering basic electrical concepts, theories, and skills.
\end{abstract}

A comparative field study was conducted in the spring of 2004. Fifty-two Indiana 4-H members enrolled in the Indiana 4-H Electric 1 project voluntarily participated in this study. The participants came from a total of nine sites from across the state of Indiana. The sites were selected from a randomly stratified sample to participate in the study. Each site received one of the two educational methodologies; traditional, face-to-face instruction or instruction via synchronous, two-way IP video.

Based on the findings of the study in comparison of the two methodologies, it was found that participants in both the traditional, face-to-face methodology and the synchronous, two-way IP video methodology were able to increase knowledge and hands-on skills from pretest to posttest. Additionally, the study found there to be no statistically significant difference in participants' knowledge or skill gains between the two educational methodologies.

\section{Introduction}

The 4-H program got its start in the early 1900's in youth corn clubs. Over time, these corn clubs and other similar clubs became of interest to Cooperative Extension Service educators. The educators discovered teaching youth new and innovative techniques could help to educate their parents at the same time. Therefore, the Cooperative Extension Service adopted work with youth as part of its mission, bringing about the creation of the $4-\mathrm{H}$ program.

Traditionally, the 4-H program, along with other program areas of the Cooperative Extension Service, used demonstrations to provide the general public with knowledge and information. This method of using demonstrations to disseminate information is still used in many workshops youth participate in today. This is an excellent opportunity for youth to learn while having the chance to interact with the instructor throughout the workshop. The downfall to these workshops is the requirement for a skilled instructor to teach the youth and a time and place for all participants to meet. ${ }^{5}$

Eventually the 4-H program developed student manuals and other paper information to provide youth guidance and knowledge pertaining to specified project areas. These paper materials were excellent resources for disseminating information and providing guidance, and are still used today. 5 
As early as the 1950's and on through the 1970's the 4-H program used television as a medium to reach youth. Instructional series for television in the areas of electricity, sciences, and emergency preparedness were aired throughout this time frame. These television programs created a media that could reach a large audience, however they lacked interaction between the youth, instructors, and presenters. ${ }^{13}$

During the 1980's, the Indiana Cooperative Extension Service paired with the Indiana Higher Education Telecommunications System (IHETS) to provide programming using the IHETS equipment. Most of the programming was done live and offered the use of video and audio in one direction, similar to television. Occasionally, participants would have the opportunity to call the instructor via a telephone to ask questions and provide feedback. Even with the use of a telephone, this was far from an interactive technology.

With tightening budgets and increased demands on staff members, the Purdue Cooperative Extension System has continued to look for methods to aid in the maximum utilization of available resources. $^{3}$

With advances in technology, the Indiana Higher Education Telecommunications System's (IHETS) high-speed computer network that is available to the Purdue Cooperative Extension Service (CES), and the forward thinking of the Director of Extension, Dr. David C. Petritz, IP video cameras were purchased for use across the state of Indiana. Originally, designed as a means to allow Purdue CES staff to attend meetings and work in statewide committees without the loss of time and money spent on travel, this technology has created the potential for use with distance education program delivery. ${ }^{8}$ It has been shown that "institutional cost savings may be realized by utilizing distance education versus place-based delivery of programs". 1

The IP video cameras, as with all distance education technology, can "provide for greater service to more individuals seeking learning opportunities." 6 The purchase of IP video cameras has created a unique opportunity to deliver programs to multiple sites across the state of Indiana and possibly the country, instantaneously. Research shows that subject matter content can be taught using distance education in a manner that is generally as effective as using traditional face-to-face methods when teaching adults. ${ }^{2,4,9}$ There has only been a small amount of research conducted that investigates how youth respond to distance education methods in comparison to traditional face-to-face settings, particularly with the use of synchronous, two-way IP video.

\section{Research Purpose}

The purpose of this research study was to determine the effectiveness of using distance education technology to teach knowledge and skill-based concepts to elementary-aged youth. The aim was to examine the effectiveness of using synchronous, two-way IP video technology to propagate knowledge and skills particularly focused around 4-H project areas. The specific objectives of the study were; one, to determine if two-way IP video technology can be used effectively to teach knowledge-based subject matter to youth and secondly, can this technology be used to effectively teach youth basic electrical wiring skills? 
For this study the Indiana 4-H Electric 1 project was used to examine youth's ability to gain knowledge and skills about electrical wiring and related topics. Specifically this study investigated, tested, and compared two different educational methodologies. The two methodologies were face-to-face, traditional workshops and synchronous, two-way IP video. The educational methodologies were compared using a pretest and posttest analysis.

The first year Indiana Electric project requires the 4-H member, (generally between 9 and 10 years of age) to have a working knowledge of electrical components, wiring techniques, and electrical safety. Generally, workshops for 4-H electric members are conducted to assist 4-H members in mastering these skills. However, there are often an inadequate number of volunteers or the volunteers available do not have the proper knowledge or skills necessary to instruct youth on skill-based topics such as the first year 4-H electric project. ${ }^{12}$ The potential for using distance education methodologies to reach youth at several sites simultaneously utilizing the expertise and knowledge of one skilled staff member or volunteer, can help fulfill the perceived inadequate number of skilled volunteers.

\section{Significance of the Study}

This study supports the use of distance education technology, such as two-way, synchronous IP video, as an effective medium for the propagation of information to elementary-aged youth. The use of two-way, synchronous IP video creates an opportunity to reach any audience spread over large geographic areas, provided that broadband internet access is available, and can bring resources such as expert knowledge and guidance to youth in situations where the same expert knowledge would otherwise not be available. This availability to provide expert knowledge to youth in the 4-H program can help 4-H members with the completion of their projects. According to Woloshuk, Brown, and Wagaman (1999) the completion of projects is important because "youth need to have the experiences of committing themselves to a challenging task and the reinforcement of successfully completing the task." 15

This technology may open the door to the creation of newer, more advanced curriculum and project areas. Since two-way, synchronous IP video can provide expert knowledge across large geographical areas, to multiple locations, it could provide education to $4-\mathrm{H}$ members from an expert, who would not be available by any other means.

\section{Method}

\section{Selection of Subject Matter Appropriate for Use with IP Video Equipment}

The researcher established specific criteria for the selection of appropriate subject matter for this study. The material selected had to have a scientific structure. The subject matter needed to be "hands-on" with activities appropriate for participants in the target audience. These hands-on activities had to be simple and measurable. After some research and in consultation with an Extension specialist who works with the 4-H program, the researcher identified the Indiana 4-H Electric 1 project as a subject matter that met these criteria. The Indiana 4-H Electric 1 project is designed for elementary-aged youth, with subject matter that involves the learning of electrical 
concepts and theories and requires participants to complete the wiring of an electrical circuit. The Indiana 4-H Electric 1 project fit the desired subject matter criteria very well.

Identification of an Instructor and Facilitator with the Proper Knowledge and Abilities to Assist at Sites

For this research study it was determined that a skilled instructor was needed; an individual who was effective at teaching youth, had experience working with youth in a workshop setting, had a clear understanding of the electrical concepts and skills covered in this project, and had experience with distance education instruction. These criteria were set for the instructor because this individual was responsible for instruction for all the sites in both the traditional, face-to-face and synchronous, two-way IP video methodologies.

After reviewing literature on distance education and particularly synchronous, two-way IP video, it was discovered that a facilitator could be an invaluable resource for both the instructor and the participants in distance education settings. ${ }^{10,11,14}$ The facilitator in this study was responsible for facilitating the learning process, administering the research evaluation tools, and collecting all research materials. Early in the study's design it was determined that a skill assessment tool would be appropriate for the selected subject matter. Ideally the facilitator had to be capable of using an evaluation tool, developed for this study, to complete the skill assessment of participants' abilities.

Required subject matter expertise and facilitator role were the primary criteria used to identify a facilitator. The facilitator had to be an individual who was familiar with electrical concepts and wiring, possessed the ability to assess the electrical wiring demonstrated by participants, and had experienced working with distance education technology.

Members of the Indiana 4-H State Electric Committee were investigated as potential instructors and facilitators. Members of the Indiana 4-H State Electric Committee have worked with the Indiana 4-H Electric project for many years. Its members have served as instructors for workshops throughout the state, served as judges for $4-\mathrm{H}$ fairs at the county and state level, and have worked with the Indiana 4-H electric camp conducted at Purdue University. These individuals were knowledgeable on the electrical concepts and skill that would be covered in this study, had experience teaching 4-H electric workshops, and had experience assessing the electrical skills of 4-H members. Despite the lack of experience with distance education technology, it was determined that members of the Indiana 4-H State Electric Committee were ideal instructor and facilitator candidates. Two members volunteered to assist with this project.

The instructor utilized a lesson plan developed by the instructor, facilitator, and researcher using the Indiana 4-H Electric 1 manual as a guide, instructional experiences from previous workshops and the pilot test, and observations made while evaluating 4-H members' working on the Electric 1 project. The facilitator was instructed on the duties to be carried out for this study. To ensure consistency these duties were reinforced via a list of procedures developed by the researcher. 
Four evaluative instruments were developed and utilized in this study. They included a: 1) knowledge gain assessment; 2) skills gain assessment; 3) demographics form; and 4) instructional perceptions questionnaire.

Knowledge Gain Assessment: A pretest and posttest design was selected for this study in the areas of knowledge gain and skill assessment. The knowledge gain pretest and posttest was based upon a 15 question knowledge gain test created by Dr. Roger Tormoehlen, professor in the Youth Development and Agricultural Education Department at Purdue University, for use with an interactive CD ROM covering the basic concepts for the Indiana $4 \mathrm{H}$ Electric 1 project. This test was modified by removing questions $5,6,11,13$, and 14 . These questions were removed since the workshop would not cover the material being addressed in these questions. The ten remaining questions were appropriate for the material covered in 4-H Electric 1 workshops and were used to create the knowledge gain test for this study.

Skill Gain Assessment: The skill gain assessment was created based on established judging standards utilized with the Indiana $4 \mathrm{H}$ Electric 1 project focusing on the participants' ability to properly attach a piece of wire (electrical conductor) to a screw terminal on a single blade switch. This skill assessment checklist was reviewed by members of the Indiana $4 \mathrm{H}$ State Electric Committee, who were considered to be experts in this area. Based on the recommendations of this committee, questions were revised from a yes or no response to Likert type scales whenever possible.

Demographics: A demographics form was created based on the Indiana 4-H enrollment form and was used to collect information about participants within this study including age, grade, gender, race/ethnicity, and involvement in the 4-H program and the 4-H electric project. Additional questions about the amount of time spent playing video games, using computers, and watching television were added to the demographics sheet based on attitude and perception surveys used in other distance education research. ${ }^{7}$ These demographics were collected to be used in the data analysis for possible correlations between these factors and participants' performance with respect to the IP video system.

Instructional Perceptions: An Instructional Perceptions form was created based on similar instruments used in other distance education research. ${ }^{7}$ The Instructional Perceptions form was created to collect information about the perceptions of the instructional experience for participants within the synchronous, two-way IP video group. This form was distributed to participants after completion of the workshop. Based on suggestions of a Purdue University faculty member with experience working with elementary aged youth, questions for the Instructional Perceptions form were modified to a simplified Likert scale using "Yes", "I Don't Know", and "No" for possible responses. These were further represented by a smiling face, a neutral face and a frowning face image. 
To properly validate the instructional procedures and evaluation tools, a pilot test was conducted at Tri Central Elementary School in Sharpsville, IN. The site consisted of approximately 20 youth from grades $3-5$.

The data collected and analyzed from the pilot test revealed that the instructor had a clear and comprehensive understanding of the electrical subject matter and concepts to be covered. The instructor demonstrated an ability to effectively communicate with the target audience. During the pilot test, participants were asked to circle any words they did not understand on the knowledge test. It was found that participants did not understand certain electrical terms such as "conductor" or "insulator." These terms could not be removed from the knowledge test, because they were specific to electrical wiring principles and concepts discussed during the workshop.

The pilot test verified that students in the targeted population were able to complete the task to be observed on the skill test. The mean knowledge and skill posttest scores of students in the pilot test increased in comparison to the mean knowledge and skill pretest scores.

Based on observations and scores from the pilot test, it was suggested that the instructor alter the lesson plan to better cover electrical subject matter and concepts addressed on the knowledge pretest and posttest.

The facilitator procedures were reviewed upon completion of the pilot test and altered to simplify the process for the facilitator and participants. In the pilot test, participants selected a random number from a hat as a personal identifier for use on the evaluation tools. The potential existed for participants to lose or forget this number. To alleviate this problem, participants were given pre-numbered evaluation tools, bundled together upon arrival at the workshop.

In the pilot test, the participants were divided into two groups. One group would complete the skill assessment, while the other completed the knowledge test. After each group had finished, the groups would switch and complete the other test. This became confusing for participants and was difficult for the facilitator to organize. For this reason, the procedures were modified so that all participants completed the knowledge pretest or posttest prior to completing the skill pretest or posttest.

\section{Identification of Counties/Sites with Proper IP Video Equipment and Sufficient Conference Room Space}

The sites and participants for this study were selected as a stratified random sample. Sites were selected from all counties within Indiana. Counties were divided into two subsets. The first subset was identified using the AgIT (Purdue University Agriculture Information Technology) IP video unit database. This database identified counties with the proper IP video equipment to serve as a synchronous, two-way IP video receive site. The other subset included all counties that did not have the proper IP video equipment.

Counties were further stratified based on the enrollment of Indiana 4-H Electric 1 members. Counties that did not have at least ten $4-\mathrm{H}$ members enrolled in the Indiana 4-H Electric 1 project 
in 2004 were not included in the sample. The counties that did not meet this requirement were dropped from the study to minimize the number of research sites necessary to obtain the desired number of participants.

Counties were assigned a number alphabetically and these numbers were randomized using a random number generator. The 4-H educator for each county was contacted via telephone to determine if any 4-H electric workshops had been conducted or were planned. For those counties where workshops had not been conducted a commitment by the educator to host the research study was obtained. Not all counties identified as potential sites for this study participated. Several counties had previously scheduled or offered similar workshops to 4-H members. Due to this, the sample was further stratified to exclude sites that had already scheduled or held a workshop covering the same electrical subject matter and concepts. Whenever a county was not willing or able to be a host site, the next available host site on the randomized list was contacted.

Table 1. Number of Research Participants for Each Site

\begin{tabular}{llccc}
\hline \multicolumn{1}{c}{ Site } & Method & $\begin{array}{c}\text { Electric 1 } \\
\text { Enrollment } \\
\text { Numbers }\end{array}$ & N & $\begin{array}{c}\text { Percentage of 4-H } \\
\text { Electric 1 Members } \\
\text { Participating }\end{array}$ \\
\hline Miami & Face-to-Face & 17 & 3 & $17.65 \%$ \\
\hline Shelby & Face-to-Face & 22 & 3 & $13.64 \%$ \\
\hline Hamilton & IP Video & 37 & 13 & $35.14 \%$ \\
\hline Hendricks & IP Video & 77 & 9 & $11.69 \%$ \\
\hline Lake & IP Video & 18 & 3 & $16.67 \%$ \\
\hline Carroll & Face-to-Face & 11 & 2 & $18.18 \%$ \\
\hline Vanderburgh & Face-to-Face & 36 & 7 & $19.44 \%$ \\
\hline Wells & IP Video & 13 & 4 & $30.77 \%$ \\
\hline Allen & Face-to-Face & 28 & 8 & $28.57 \%$ \\
\hline
\end{tabular}

The research study originally consisted of eight sites. As can be seen in Table 1, as the study progressed it became apparent that the number of participants in the traditional, face-to-face group was significantly less than the number of participants in the synchronous, two-way IP video group. As a solution, Allen County was added as a fifth face-to-face site. Allen County was selected based on its availability to host a workshop. Many counties had already conducted a workshop or were past the deadline for completion of projects.

Table 1 shows the potential number of youth who could have participated in the study based on the fact that they were enrolled in the $1^{\text {st }}$ year Indiana $4-\mathrm{H}$ electric project. With $4-\mathrm{H}$ activities/workshops being optional the number of youth who actually participate in any given workshop is less than the potential.

\section{Experimental Procedure}

For purposes of this study a random methodology was used to select the counties that participated in the study. Once a county was selected and assigned a treatment (face-to-face 
instruction or two-way synchronous IP video) all subjects in that respective county received that treatment. The students were not sub-divided within the counties.

For each workshop site the facilitator, and whenever possible, the researcher traveled to the workshop location. Once at the site, the facilitator would setup tables, layout tools, and organize teaching and demonstration equipment. Once participants arrived at the site, the facilitator administered the multiple choice based, knowledge gain pretest. The participants worked through the test at their pace and parents were asked not to help their child during this portion of the study. After observing participants at the first two sites completing this process, it was decided the facilitator or instructor should read the pretest aloud to participants. This was done to compensate for words on the written test that may have been above the participants' reading level, but were required based on the subject matter covered.

When all participants had completed the written test, they were asked to complete a skill assessment pretest. This test consisted of a simple task of connecting a piece of wire to a single blade, single throw switch. Participants were provided with a variety of tools, a piece of wire and a switch. The facilitator gave a single instruction, "please attach the wire to the switch." These instructions were intentionally vague, so as not to lead the participants to a correct or incorrect solution for this task. Following completion of the skill assessment pretest, the facilitator collected and graded each participant's switch and wire using the skill assessment sheet.

With the pretests completed, instruction began. The instructor covered the exact same knowledge and skill-based content for both treatment groups. The only difference was whether the instructor was in the room with the students (control group) or working with them via a twoway synchronous IP video connection (experimental group). For both methodologies all instruction was provided by the instructor. The onsite facilitator did not provide any instruction or answer any questions. For the IP video trainings professional production studios available on the Purdue University campus were not used for this study. These facilities were expensive to use and would not be practical or affordable for everyday use with 4-H workshops. It was decided to use facilities that were more likely to be utilized in a 4-H workshop setting with synchronous, two-way IP video. This was done to make the study applicable to future 4-H workshops. The on-campus production site contained two camera's one for wide angle shots and one for close-ups.

Following completion of the instructional segments, students were administered a written posttest. As with the pretest the questions were read aloud. Upon completion of the written posttest, participants were asked to complete the skill assessment posttest. As with the skill pretest, the posttest consisted of a simple task of connecting a piece of wire to a single blade, single throw switch. Participants were provided with a variety of tools, a piece of wire and a switch. The facilitator gave the same single instruction, "please attach the wire to the switch." The facilitator then assessed each participant's efforts using the skill assessment sheet.

Once participants completed the posttests, the facilitator or instructor reviewed each of the knowledge test questions and explained the correct answers. The facilitator then reviewed the skill test assessment; discussing each item the facilitator evaluated using the skill assessment sheet. 
The entire workshop from beginning to end including pretests and posttests took between two and two and a half hours.

\section{Results and Discussion}

\section{Participant Demographics}

A comparison of the two treatment groups found that no statistic difference was present between the groups. Table 2 shows the average participant demographics by treatment group.

Table 2: Participant demographics by treatment group.

\begin{tabular}{lccc}
\hline Variable & Face-to-face & Two-way IP Video & Chi Square \\
\hline Age (mean) & 8.8 & 10.4 & 0.0930 \\
Grade (mean) & $4^{\text {th }}$ & $4^{\text {th }}$ & 0.8251 \\
Years in 4-H (mean) & 1.9 & 1.6 & 0.4721 \\
Gender & $69.6 \% \mathrm{M}, 30.4 \% \mathrm{~F}$ & $75.9 \% \mathrm{M}, 24.1 \% \mathrm{~F}$ & 0.6112 \\
\hline
\end{tabular}

\section{Knowledge Tests}

Participants were administered a 10 question knowledge pretest, covering basic electrical concepts, principles and subject matter, to establish a baseline knowledge level measurement prior to instruction and hands-on learning.

For the 52 participants in this study, the number of mean correct responses for the knowledge pretest score was $6.21(62.1 \%)$ out of the 10 possible points with a standard deviation of 2.40 . The median and mode scores were both six. Scores ranged from a minimum of two correct to a maximum of 10 correct. Table 3 shows the mean knowledge pretest scores by site. The mean number of correct responses on the knowledge pretest score for the traditional, face-to-face group was $6.09(60.9 \%)$. The mean number of correct responses on the knowledge pretest score for the synchronous, two-way IP video group was 6.31 (63.1\%). A t-test was used to analyze any possible differences in the knowledge pretest scores. The t-test returned a value of 0.7420 , meaning there is no statistical difference in the knowledge pretest scores of the two methodologies. 
Table 3. Mean Knowledge Pretest Scores by Site

\begin{tabular}{ccccc}
\hline Location & Methodology & N & Mean & Standard Deviation \\
\hline Site 1 & Face-to-Face & 3 & 7.67 & 2.08 \\
Site 2 & Face-to-Face & 3 & 4.33 & 1.53 \\
Site 6 & Face-to-Face & 2 & 6.00 & 0.00 \\
Site 7 & Face-to-Face & 7 & 5.71 & 2.14 \\
Site 9 & Face-to-Face & 8 & 6.50 & 2.27 \\
Total & & 23 & 6.09 & 2.09 \\
\hline Site 3 & IP Video & 13 & 7.00 & 2.86 \\
Site 4 & IP Video & 9 & 6.00 & 2.55 \\
Site 5 & IP Video & 3 & 6.00 & 1.73 \\
Site 8 & IP Video & 4 & 5.00 & 2.94 \\
Total & & 29 & 6.31 & 2.65 \\
\hline
\end{tabular}

Upon completion of the educational workshop, participants were administered the knowledge posttest. The knowledge posttest was the same as the knowledge pretest.

For the 52 participants, the mean knowledge posttest score was 7.48 (74.8\%) out of 10 possible points with a standard deviation of 1.90. The median and mode for the knowledge posttest were both eight correct responses. The scores ranged from a minimum of three correct responses to a maximum of ten correct responses. The mean knowledge posttest score for the traditional, face-to-face group was 7.96. The mean knowledge posttest score for the synchronous, two-way IP video group was 7.10. Table 4 shows the mean posttest scores for participants by site. A t-test analysis was done to investigate any potential differences in participants' knowledge posttest scores. The t-test returned a value of 0.1094 , meaning there was no statistical difference between the methodologies.

Table 4. Mean Knowledge Posttest Scores by Site

\begin{tabular}{ccccc}
\hline Location & Methodology & N & Means & Standard Deviation \\
\hline Site 1 & Face-to-Face & 3 & 7.67 & 1.15 \\
Site 2 & Face-to-Face & 3 & 5.67 & 1.53 \\
Site 6 & Face-to-Face & 2 & 8.00 & 0.00 \\
Site 7 & Face-to-Face & 7 & 8.71 & 1.11 \\
Site 9 & Face-to-Face & 8 & 8.25 & 1.67 \\
Total & & 23 & 7.96 & 1.58 \\
\hline Site 3 & IP Video & 13 & 7.77 & 1.74 \\
Site 4 & IP Video & 9 & 6.67 & 2.55 \\
Site 5 & IP Video & 3 & 5.67 & 0.58 \\
Site 8 & IP Video & 4 & 7.00 & 2.45 \\
Total & & 29 & 7.10 & 2.08 \\
\hline
\end{tabular}

Knowledge gain scores were calculated by subtracting each participant's knowledge pretest score from their posttest score. The mean knowledge gain in correct answers for all participants 
was 1.27 questions with a standard deviation of 2.12. Table 5 shows the mean knowledge gain or loss for each site. The mean knowledge gain for the traditional, face-to-face group was 1.87. The mean knowledge gain for the synchronous, two-way IP video group was 0.79. A paired t-test analysis revealed a statistically significant increase in participants' knowledge score from pretest to posttest. Another t-test was used to analyze any differences in the participants' knowledge gain between the two methodologies. The t-test returned a value of 0.0679 which indicated there was not a statistically significant difference between the methodologies based on an alpha of 0.05 or less being the basis for statistical significance.

Table 5. Mean Knowledge Gain (Loss) by Site

\begin{tabular}{ccccccc}
\hline & & $\begin{array}{c}\text { Knowledge } \\
\text { Pretest } \\
\text { Lecation }\end{array}$ & $\begin{array}{c}\text { Knowledge } \\
\text { Posttest } \\
\text { Means }\end{array}$ & $\begin{array}{c}\text { Knowledge } \\
\text { Gain Means }\end{array}$ & $\begin{array}{c}\text { Standard } \\
\text { Deviation }\end{array}$ \\
\hline Site 1 & Face-to-Face & 3 & 7.67 & 7.67 & 0.00 & 2.65 \\
Site 2 & Face-to-Face & 3 & 4.33 & 5.67 & 1.33 & 2.31 \\
Site 6 & Face-to-Face & 2 & 6.00 & 8.00 & 2.00 & 0.00 \\
Site 7 & Face-to-Face & 7 & 5.71 & 8.71 & 3.00 & 1.63 \\
Site 9 & Face-to-Face & 8 & 6.50 & 8.25 & 1.75 & 1.83 \\
Total & & 23 & 6.09 & 7.96 & 1.87 & 1.96 \\
\hline Site 3 & IP Video & 13 & 7.00 & 7.77 & 0.77 & 2.09 \\
Site 4 & IP Video & 9 & 6.00 & 6.67 & 0.67 & 2.35 \\
Site 5 & IP Video & 3 & 6.00 & 5.67 & -0.33 & 2.08 \\
Site 8 & IP Video & 4 & 5.00 & 7.00 & 2.00 & 2.16 \\
Total & & 29 & 6.31 & 7.10 & 0.79 & 2.14 \\
\hline
\end{tabular}

\section{Skill Tests}

Upon completion of the knowledge test, participants were given a skill assessment test to establish a skill level baseline. Participants were asked to complete a simple task of attaching a wire to the screw terminal of a single blade, single throw switch.

The study's 52 participants had a mean skill pretest score for correctly attaching the wire of 5.38 $(22.42 \%)$ with a standard deviation of 7.38. The median and mode scores for the skill pretest were both zero. The scores ranged from a minimum of 0 to a maximum of 20 out of the 24 points possible. The mean skill pretest score for the traditional, face-to-face group was 4.07. The mean skill pretest score for the synchronous, two-way IP video group was 6.41. Table 6 shows the participants' mean skill pretest scores by site. A t-test comparing the skill pretest scores of participants in each methodology returned a value of 0.2587 . The t-test showed no statistical difference in the participants' skill pretest scores between methodologies. 
Table 6. Mean Skill Pretest Scores by Site

\begin{tabular}{ccccc}
\hline Location & Methodology & N & Means & Standard Deviation \\
\hline Site 1 & Face-to-Face & 3 & 12.17 & 7.94 \\
Site 2 & Face-to-Face & 3 & 2.50 & 3.12 \\
Site 6 & Face-to-Face & 2 & 0.00 & 0.00 \\
Site 7 & Face-to-Face & 7 & 2.93 & 5.57 \\
Site 9 & Face-to-Face & 8 & 3.63 & 6.31 \\
Total & & 23 & 4.07 & 6.25 \\
\hline Site 3 & IP Video & 13 & 6.04 & 8.04 \\
Site 4 & IP Video & 9 & 8.11 & 8.61 \\
Site 5 & IP Video & 3 & 4.83 & 8.37 \\
Site 8 & IP Video & 4 & 5.00 & 10.00 \\
Total & & 29 & 6.41 & 8.13 \\
\hline
\end{tabular}

For the skill posttest, like the skill pretest, participants were asked to attach a wire to the screw terminal of a single blade, single throw switch. For the 52 participants, the mean skill posttest score was 19.17 (79.9\%) out of 24 possible points with a standard deviation of 5.36. The scores ranged from a minimum of 0 correct to a maximum of 24 correct. The median for the skill posttest scores was 20 correct. The mode for the skill posttest scores was 24 . Table 7 shows the participants' mean posttest scores by site. The mean skill posttest score for the traditional, face-to-face group was 19.76. The mean skill posttest score for the synchronous, two-way IP video group was 18.71. A t-test was used to determine if there was any statistical difference in the skill posttest scores for participants in each methodology. The t-test returned a value of 0.4871 which indicates that there was no statistical difference between the two methodologies for participants' skill posttest scores.

Table 7. Mean Skill Posttest Scores by Site

\begin{tabular}{ccccc}
\hline Location & Methodology & $\mathrm{N}$ & Means & Standard Deviation \\
\hline Site 1 & Face-to-Face & 3 & 23.17 & 1.44 \\
Site 2 & Face-to-Face & 3 & 17.83 & 6.83 \\
Site 6 & Face-to-Face & 2 & 20.75 & 3.18 \\
Site 7 & Face-to-Face & 7 & 19.29 & 4.12 \\
Site 9 & Face-to-Face & 8 & 19.38 & 4.98 \\
Total & & 23 & 19.76 & 4.44 \\
\hline Site 3 & IP Video & 13 & 20.23 & 4.35 \\
Site 4 & IP Video & 9 & 15.33 & 8.79 \\
Site 5 & IP Video & 3 & 18.83 & 1.26 \\
Site 8 & IP Video & 4 & 21.25 & 2.10 \\
Total & & 29 & 18.71 & 6.04 \\
\hline
\end{tabular}

Skill gain scores were calculated in the same manner as the knowledge gain scores, by subtracting each participant's skill pretest score from their skill posttest score. The mean skill gain in correct answers for all participants was 13.80 with a standard deviation of 9.43. Table 8 shows the mean skill gain or loss for each site in this study. The mean skill gain for the traditional, face-to-face group was 15.70. The mean skill gain for the synchronous, two-way IP 
video group was 12.29. A paired t-test analysis revealed that there was a statistically significant increase in participants' skill score from pretest to posttest. A t-test was used to determine if participant's skill gains were statistically significant between the two methodologies. The t-test returned a value of 0.1712 , meaning there was not a statistical difference in participants' skill gains between the two methodologies.

Table 8. Mean Skill Gain (Loss) by Site

\begin{tabular}{cccccc}
\hline Location & Methodology & $\begin{array}{c}\text { Skill Pretest } \\
\text { Means }\end{array}$ & $\begin{array}{c}\text { Skill } \\
\text { Posttest } \\
\text { Means }\end{array}$ & $\begin{array}{c}\text { Skill Gain } \\
\text { Means }\end{array}$ & $\begin{array}{c}\text { Standard } \\
\text { Deviation }\end{array}$ \\
\hline Site 1 & Face-to-Face & 12.17 & 23.17 & 11.00 & 6.50 \\
Site 2 & Face-to-Face & 2.50 & 17.83 & 15.33 & 4.19 \\
Site 6 & Face-to-Face & 0.00 & 20.75 & 20.75 & 3.18 \\
Site 7 & Face-to-Face & 2.93 & 19.29 & 16.36 & 5.93 \\
Site 9 & Face-to-Face & 3.63 & 19.38 & 15.75 & 6.75 \\
Total & & 4.07 & 19.76 & 15.70 & 5.95 \\
\hline Site 3 & IP Video & 6.04 & 20.23 & 14.19 & 10.64 \\
Site 4 & IP Video & 8.11 & 15.33 & 7.22 & 13.62 \\
Site 5 & IP Video & 4.83 & 18.83 & 14.00 & 7.40 \\
Site 8 & IP Video & 5.00 & 21.25 & 16.25 & 10.05 \\
Total & & 6.41 & 18.71 & 12.29 & 11.35 \\
\hline
\end{tabular}

Sites’ Chronological Order

A two-way ANOVA statistical analysis was conducted to examine the effects of the chronological order of the sites on the knowledge and skill gain of participants. As seen in Table 9, the order of sites proved to be statistically significant for knowledge gain. Order was not statistically significant for skill gain, as seen in Table 10.

Table 9. ANOVA Analysis of Sites' Chronological Order Based on Knowledge Gain

\begin{tabular}{lcrrrr}
\hline Source & DF & Sum of Squares & Mean Square & F Value & Pr > F \\
\hline Order & 1 & 23.815 & 23.815 & 5.370 & $0.027^{*}$ \\
Method & 1 & 3.848 & 3.848 & 0.870 & 0.358 \\
\hline
\end{tabular}

* significance level .05

Table 10. ANOVA Analysis of Sites' Chronological Order Based on Skill Gain

\begin{tabular}{lcrrrc}
\hline Source & DF & Sum of Squares & Mean Square & F Value & Pr $>$ F \\
\hline Order & 1 & 5.564 & 5.564 & 0.070 & 0.794 \\
\hline Method & 1 & 263.425 & 263.425 & 3.270 & 0.079 \\
\hline
\end{tabular}




\section{Conclusions}

Based on findings from this analysis, several conclusions can be made about the use of synchronous two-way IP video as an educational methodology within the 4-H program and with elementary-aged youth.

Both the traditional, face-to-face methodology and the synchronous, two-way IP video methodology are viable educational methodologies for use in non-formal educational settings to transfer knowledge and teach skills. A paired t-test analysis indicated a significant gain between the participant's pretest and posttest scores for both knowledge and skills. The mean knowledge gain for participants involved in this study was 1.27 questions. Participants on average increased their correct responses on the posttest by $12.7 \%$.

Both the traditional, face-to-face methodology and the synchronous, two-way IP video methodology can be used effectively to teach hands-on skills. The mean skill gain for participants involved in this study was 13.8 , representing a $57.5 \%$ increase from the skill pretest to the skill posttest.

There was not a statistically significant difference in the knowledge gain of participants in the synchronous, two-way IP video methodology verses participants in the traditional, face-to-face methodology, indicating that one methodology is not statistically better than the other. There was no statistical difference in the hands-on skill gain of participants in the synchronous, two-way IP video methodology verses participants in the traditional, face-to-face methodology.

An ANOVA analysis was used to find any possible statistical differences in age, grade, gender, frequency of video game play by participants per week, availability of a computer in the participant's home, hours of computer use by participants per day, and hours of television watched per day. Based on the ANOVA analysis, these factors were not statistically significant for participants' skill gain, based on method of instruction.

In summary, neither method was found to be significantly better than the other at increasing knowledge and/or skills. This implies that two-way, synchronous IP video is an acceptable methodology for teaching knowledge and skills when compared to the traditional face-to-face method.

\section{Bibliography}

1. Cecil, K. \& Feltes, D. (2002). Distance education-A case study in practical application. Journal of Extension, 40 (5). Retrieved October 15, 2003, from http://www.joe.org/joe/2002october/tt4.shtml

2. Hoyt, J. E. (1999). Does the delivery method matter?: Comparing technologically delivered distance education with on-campus instruction. Orem, UT: Department of Institutional Research, Utah Valley State College. Retrieved September 29, 2003, from http://www.uvsc.edu/ir/research/distpub.pdf 
3. Jischke, M. C. (2003, February, 14). President Martin C. Jischke's comments to the Purdue University Board of Trustees. Retrieved September 19, 2003, from http://news.uns.purdue.edu/UNS/html3month/030214.Jischke.BOT.html

4. King, C. \& Fricker, B. (2002). Multimodal curriculum delivery in distance education. Journal of Distance Education, 17 (2), 102-111. Retrieved September 29, 2003, from http://cade.athabascau.ca/vol17.2/king_fricker.pdf

5. Kirkpatrick, E. E., \& Smith, M. F. (1990). 4-H in Indiana: 1904-1990, a record of achievement. West Lafayette, IN: Purdue Research Foundation.

6. Mielke, D. (1999). Effective teaching in distance education. (ERIC Document Reproduction Service No. ED436528)

7. Ortega, R., R. (2003). Analysis and evaluation of the effectiveness of gearing up: Production agricultural safety training for youth, the computer assisted instruction/multimedia farm tractor and machinery safety curriculum. Unpublished master's thesis, Purdue University, West Lafayette.

8. Petritz, D. C. (personal communication, Purdue University, West Lafayette, IN, May 22, 2003)

9. Restauri, S. L., King, F. L., \& Nelson, J. G. (2001). Assessment of students' ratings for two methodologies of teaching via distance learning: An evaluative approach based on accreditation. (ERIC Document Reproduction Service No. ED460148)

10. Ricketts, J., Hoelscher-Day, S., Begeman, G., \& Houtkooper, L. (2001). Interactive distance learning effectively provides winning sports nutrition workshops. Journal of Extension 39 (5). Retrieved October 30, 2003, from http://www.joe.org/joe/2001/october/a1.html

11. Telg, R. W. (1999). Instructional methods for distance education. Agricultural Education \& Communication Department, Florida Cooperative Extension Service, Institute of Food and Agricultural Sciences, University of Florida. Retrieved September 26, 2003, from http://edis.ifas.ufl.edu/BODY_WC026

12. Tormoehlen, R. L. (personal communication, Purdue University, West Lafayette, IN, August 10, 2003)

13. Wessel, T., \& Wessel, M. (1982). 4-H: An American idea 1900-1980, A history of 4-H. Chevy Chase, MD: National 4-H Council.

14. Willis, B. (2004). Distance education at a glance. Retrieved May 13, 2004, from http://www.uidaho.edu/eo/distglan.html

15. Woloshuk, J. M., Brown, G., \& Wagaman, G. D. (1999). 4-H projects: Is completion important? Journal of Extension, 37 (5). Retrieved August 19, 2004, from http://www.joe.org/joe/1999october/rb5.html 